\title{
WETENSCHAP
}

\section{De processuele positie van de aansprakelijk gestelde bestuurder}

\author{
H.J. Vetter
}

\section{Inleiding}

Met enige regelmaat loopt men in de ondernemingsrechtelijke aansprakelijkheidspraktijk aan tegen ogenschijnlijk eenvoudig te beantwoorden aansprakelijkheidsvragen die bij nader inzien toch wat lastiger blijken te zijn. Het gaat mij in deze bijdrage om de processuele positie van de (al of niet) hoofdelijk aansprakelijk gestelde bestuurder. Enkele recente uitspraken over de aansprakelijkheid van de bestuurder op grond van onrechtmatige daad, mede op basis van art. 2:11 Burgerlijk Wetboek (BW), geven aanleiding tot een bespiegeling over de mogelijkheden tot verweer door de (hoofdelijk) aansprakelijk gestelde bestuurder in het licht van het leerstuk van het gezag van gewijsde.

\section{Een art. 2:11 BW-casus}

Om de lezer wat warm te laten lopen voor het onderwerp schets ik eerst de vraag die in 2018 beantwoord moest worden door de kantonrechter van de Rechtbank Midden-Nederland. ${ }^{1}$ De casus in het kort: een $\mathrm{bv}^{2}$ (hierna: BV A) gaat een huurovereenkomst aan met Achmea DRPF. De huur wordt nooit betaald. BV A wordt aangesproken tot nakoming. Maar bovendien spreekt Achmea DRPF de enig bestuurder van de vennootschap, BV B, aan alsmede de enig bestuurder van deze vennootschap, de natuurlijk persoon $C$, de zogenaamde indirect bestuurder. De stelling van Achmea DRPF is dat voor $C$, en dus voor BV B, van meet af aan duidelijk was dat BV A haar huurbetalingsverplichting niet zou kunnen nakomen. Achmea DRPF baseert de vordering op BV B aldus op schending van de Beklamelnorm. ${ }^{3}$ Van BV B en $C$ vordert zij, uit hoofde van onrechtmatige daad, een schadevergoeding ter hoogte van de niet-betaalde huurtermijnen. BV B en C laten verstek gaan, zodat ze hoofdelijk worden veroordeeld tot vergoeding van de gevorderde schade. BV B laat het erbij zitten: de uitspraak tegen haar gewezen gaat in kracht van gewijsde. Maar $C$ komt in verzet. In die verzetprocedure komt $\mathrm{C}$ op de proppen met een relaas waarvan de kern is dat de Beklamel-norm niet

1 Rb. Midden-Nederland 24 januari 2018, ECLI:NL:RBMNE:2018:122, RO 2018/28.

2 De uitspraak is ongelukkigerwijs zo geanonimiseerd dat niet duidelijk is om welke rechtsvorm het gaat; op basis van de feitenconstellatie neem ik aan dat het om een bv gaat. 
geschonden is, en dat het gedrag van een derde er de oorzaak van was dat BV A niet kon nakomen. De kantonrechter negeert dat relaas, want:

'Als definitief vaststaat dat [BV B] een ernstig en persoonlijk verwijt gemaakt kan worden als bestuurder, dan treft dat ook [C]. [C] probeert zichzelf te disculperen. Maar dat kan niet meer: hij is de enige bestuurder in [BV B] en kan binnen die vennootschap op niemand anders wijzen die de schuld heeft. Niemand anders dan hij is namelijk verantwoordelijk voor wat [BV B] deed. En daarbuiten kon alleen [BV B] zelf op een ander wijzen, maar dat liet zij na. $\mathrm{Nu}$ nog betogen dat [BV B] niets is te verwijten, is zinloos. Het tegendeel staat door het verstekvonnis definitief vast.'

Hoewel de kantonrechter dat in het vonnis niet met zoveel woorden zegt, is duidelijk dat hij het bepaalde in art. 2:11 BW en de daaraan door de Hoge Raad gegeven uitleg in zijn arrest Le Roux toepast. ${ }^{4}$ Mijn vraag: is dit nou inderdaad de consequentie van de toepassing van art. 2:11 BW, zoals uitgelegd door de Hoge Raad? Voordat ik aan de behandeling van die vraag toekom, eerst een korte verkenning van de processuele positie van de hoofdelijk aansprakelijke debiteur in het algemeen.

\section{De processuele positie van de hoofdelijk aansprakelijke debiteur in het algemeen}

Op iedere hoofdelijk verbonden debiteur rust de verplichting de volledige verschuldigde prestatie te voldoen, art. 6:7 lid 1 BW. De crediteur kan alle hoofdelijk verbonden debiteuren in rechte betrekken en nakoming vorderen. Doorgaans gebeurt dat met een toevoeging in het petitum luidend: 'des dat de een betalende, de anderen zijn bevrijd'. ${ }^{5}$ Maar doet de crediteur dat niet, en beperkt hij zich tot het aanspreken van slechts één (A) van de hoofdelijk verbonden debiteuren $A$ en $\mathrm{B}$, dan zal het rechterlijk oordeel in verhouding tot A de mede hoofdelijk verbonden $B$ niet raken. Het onherroepelijk geworden vonnis gewezen tussen de crediteur en gedaagde A heeft, met andere woorden, geen gezag van gewijsde (art. 236 lid 1 Wetboek van Burgerlijke Rechtsvordering (Rv)) in de relatie tussen de crediteur en B. ${ }^{6}$ Een rechterlijke uitspraak bindt immers alleen de partijen waartussen zij wordt gedaan. Dat betekent dat de hoofdelijk verbonden B, eenmaal aangesproken, alle registers kan opentrekken: hij kan (nogmaals) de weren naar voren brengen die $\mathrm{A}$ al had aangevoerd, maar hij kan ook met nieuwe weren op de proppen komen. Nieuwe weren die A misschien ook ten dienste stonden, maar door een omissie of uit onwetendheid niet naar voren zijn gebracht. Het is goed denkbaar dat de vordering, gebaseerd op exact dezelfde feitelijke stellingen van de eiser, tegen de ene hoofdelijk verbonden debiteur in rechte wel, maar tegen de andere hoofdelijk aansprakelijke niet wordt toegewezen, en dat als gevolg van een

$4 \quad$ HR 17 februari 2017, ECLI:NL:HR:2017:275.

5 Asser/Sieburgh 6-I 2016/112.

6 Aldus o.a. W.H. van Boom, Hoofdelijke verbintenissen, Den Haag: Boom juridisch 2016, p. 229. 
verschil in verweer. ${ }^{7}$ Sterker, het risico van separate procedures tegen hoofdelijk verbonden debiteuren is dat, op basis van dezelfde stellingen en dezelfde weren, door verschillende rechters tegenstrijdige uitspraken worden gedaan. Onwenselijk vanzelfsprekend, maar de rechter heeft geen instrumentarium om dat te voorkomen. De wettelijke regeling die het mogelijk maakt alsnog een derde in een lopende procedure te betrekken, art. $118 \mathrm{Rv}$, biedt in dergelijke situaties, naar moet worden aangenomen, geen soelaas. ${ }^{8}$

\section{De op grond van Boek 2 BW hoofdelijk aansprakelijke bestuurder}

Boek 2 BW bevat verschillende gronden voor hoofdelijke aansprakelijkheid van bestuurders van rechtspersonen. Ik wijs met name op de aansprakelijkheid van bestuurders wegens onbehoorlijke taakvervulling (art. 2:9 BW), voor rechtshandelingen zolang is nagelaten de $\mathrm{nv}$ of bv in te schrijven in het handelsregister (art. 2:69/180 BW), ${ }^{9}$ voor de publicatie van misleidende financiële verslaglegging (art. 2:139/249 BW) en, last but not least, voor kennelijk onbehoorlijk bestuur tegenover de faillissementscurator (art. 2:138/248 BW). Dit zijn gevallen van hoofdelijke aansprakelijkheid, maar wel van een bijzondere aard. De hoofdelijke verbondenheid is geënt op de collectieve bestuursverantwoordelijkheid: 'het bestuur' is collectief in de fout gegaan. Individuele bestuurders kunnen, voor zover de wet daartoe de ruimte biedt, feiten en omstandigheden naar voren brengen die leiden tot disculpatie (art. 2:9 lid 2, 2:138/248 lid 3 en 2:139/249, laatste zin, BW) of matiging (art. 2:138/248 lid 4, laatste zin, BW). Een ontsnapping voor de bestuurder van de nv of bv die meent dat het tekortschieten in de nakoming van de verplichtingen genoemd in art. 2:69 of 2:180 BW wellicht aan anderen, maar niet aan hem te wijten is, is er - althans naar de letter van de wet - niet.

Het kan voorkomen dat de faillissementscurator (art. 2:9 of 2:138/248 BW), de rechtspersoon (art. 2:9 BW) of een crediteur (art. 2:69/180 of 2:139/249 BW) niet alle bestuurders (laten we zeggen: A, B en $C$ ) in rechte betrekt, maar zich beperkt tot een van de bestuurders, bijvoorbeeld de meest draagkrachtige (A). Leidt de procedure tot veroordeling van $\mathrm{A}$, dan staat, als dat oordeel in kracht van gewijsde is gegaan, in relatie tot A vast dat het bestuur over de schreef is gegaan en sprake is geweest van onbehoorlijke taakvervulling door het bestuur, van kennelijk onbehoorlijk bestuur, of van bestuursaansprakelijkheid op de voet van het bepaalde in art. 2:69/180 dan wel 2:139/249 BW. Het gezag van gewijsde is er ten opzichte

7 Dat ligt besloten in HR 18 december 2015, ECLI:NL:HR:2015:3637, zie m.n. r.o. 3.5.

8 Zie de beschouwing van J.A. Möhlmann, Herstel van verzuim en strijd tegen tegenstrijdige beslissingen. Over de oproeping van derden ex artikel 118 Rv, TCR 2017, afl. 3, p. 100-110, m.n. p. 108, waar de schrijver concludeert dat art. $118 \mathrm{Rv}$ niet strekt tot het tegengaan van tegenstrijdige beslissingen.

9 De vereniging (art. 2:29 lid 2 BW) en de stichting (art. 2:289 lid 2 BW) kennen een vergelijkbare regeling, die net iets anders is opgezet: (alleen) de handelende bestuurder is hoofdelijk naast de vereniging of stichting gebonden voor rechtshandelingen die zijn verricht voor de inschrijving in het handelsregister. 
van $\mathrm{A}$, maar niet ten opzichte van de niet-gedaagden $\mathrm{B}$ en $C .{ }^{10}$ Mocht het ervan komen dat $\mathrm{B}$ en $\mathrm{C}$ alsnog in rechte worden betrokken, dan kan de discussie over het tekortschieten van het bestuur nogmaals volledig gevoerd worden, en kan de uitkomst in dat geding een andere zijn. De omstandigheid dat A, B en C samen het bestuur van de rechtspersoon voor hun rekening hebben genomen en dus een gezamenlijke verantwoordelijk hadden, doet daar niet aan af. Een lamlendig verweer in rechte van A kan B en C niet de das omdoen. Dat tegenover A wel, maar tegenover $B$ en $C$ niet in rechte vast komt te staan dat van, bijvoorbeeld, onbehoorlijke taakvervulling sprake is geweest, schept een interessante situatie. Een boeiende twist over de interne draagplicht tussen de bestuurders onderling van de door A op grond van diens veroordeling betaalde vergoeding, op de voet van het bepaalde in art. 6:10 lid $1 \mathrm{BW}$, kan wellicht nog volgen, maar daar gaat het nu niet om.

\section{De aansprakelijkheidsregel van art. 2:11 BW bij onrechtmatige daad bij één indirect (tweedegraads) bestuurder}

Ik kom terug op de casus die ik hierboven ter introductie schetste en werd beoordeeld door de Rechtbank Midden-Nederland. ${ }^{11}$ Wat is de processuele positie van de indirect (tweedegraads) bestuurder/natuurlijk persoon (C) die, bij verstek, op de voet van het bepaalde in art. 2:11 BW is veroordeeld omdat de bestuurderrechtspersoon (BV B) de Beklamel-norm heeft geschonden? Duidelijk is, na het voorgaande, dat het oordeel over de gedragingen van BV B tegenover haar gezag van gewijsde heeft; zij heeft geen rechtsmiddel aangewend, zodat het vonnis in kracht van gewijsde is gegaan. Het oordeel van de kantonrechter dat indirect bestuurder $C$ nu niets meer te berde kan brengen tegen zijn eigen veroordeling, betekent per saldo dat het oordeel over de verhouding tussen crediteur Achmea DRPF en BV B hem, C, ook bindt. Het gezag van gewijsde wordt daarmee uitgebreid tot een derde, en dat lijkt te wringen met het uitgangspunt dat besloten ligt in art. 236 lid 1 Rv: het rechterlijk oordeel bindt alleen de partijen die in rechte bij de beoordeling van het geschil zijn betrokken. Is dit nu inderdaad het gevolg van de door de Hoge Raad aan art. 2:11 BW gegeven uitleg in zijn arrest Le Roux? De Hoge Raad heeft in zijn arrest de aansprakelijkheid van de bestuurder-rechtspersoon geënt op onrechtmatige daad binnen de reikwijdte van art. 2:11 BW getrokken. ${ }^{12}$ Stel nu - zoals in de door de Hoge Raad beoordeelde casus aan de orde was - dat de bestuurder-rechtspersoon twee natuurlijke personen ( $\mathrm{X}$ en $\mathrm{Y}$ ) als bestuurders heeft. Reeds het gedrag van een van beiden (laten we zeggen: $\mathrm{X}$ ) zal,

10 Art. 236 lid 1 Rv. Asser Procesrecht/Van Schaick 2 2016/150: 'Een rechterlijke uitspraak bindt alleen de partijen tussen wie zij wordt gedaan.'

11 Zie noot 1.

12 In dit tijdschrift is tweemaal aandacht besteed aan het arrest, namelijk in J.B. Huizink, De rechtspersoon-bestuurder en art. 2:11 BW, O\&F 2018, afl. 2, p. 5-10 en H.J. Vetter, Waarom zou de aansprakelijkheid wegens onrechtmatige daad zijn uitgesloten?, O\&F 2017, afl. 4, p. 63-72. 
mits dat wordt toegerekend aan de bestuurder-rechtspersoon, ${ }^{13}$ het onrechtmatig karakter van het handelen van de bestuurder-rechtspersoon vestigen. De medebestuurder Y 'hangt' ook, zo volgt uit het arrest uit 2017, tenzij Y in staat is zich te disculperen; op hem rusten in dat verband de stelplicht en de bewijslast, zo heeft de Hoge Raad ons geleerd. De Hoge Raad heeft daardoor in het verband van art. 2:11 BW ook bij onrechtmatig handelen een collectieve bestuurdersaansprakelijkheid tot uitgangspunt genomen. In het licht van de uitspraak van de Rechtbank Midden-Nederland citeer ik uit het arrest van de Hoge Raad:

'De onherroepelijk vastgestelde aansprakelijkheid van Holding als bestuurder van [A] jegens [verweerster] ingevolge art. 6:162 BW (...), rust ingevolge art. 2:11 BW tevens hoofdelijk op [eiser], behoudens door hem te stellen en zo nodig te bewijzen omstandigheden op grond waarvan de conclusie gerechtvaardigd is dat hem persoonlijk geen ernstig verwijt terzake kan worden gemaakt.'

De vraag die opkomt, is: wanneer is deze aansprakelijkheid van de rechtspersoonbestuurder ('Holding') onherroepelijk vast komen te staan? Is dat ook het geval als de rechtspersoon-bestuurder in rechte is betrokken en verstek heeft laten gaan, zodat - zonder dat op enig verweer acht geslagen hoefde te (en kon) worden - is geoordeeld dat de rechtspersoon-bestuurder onrechtmatig heeft gehandeld jegens crediteuren van de bestuurde vennootschap? Dat zou zuur zijn voor $\mathrm{Y}$, wanneer hij bijvoorbeeld recent is afgetreden als bestuurder van de rechtspersoon-bestuurder, en dus niet bij machte was om de rechtspersoon-bestuurder (Holding) naar behoren verweer te laten voeren. Naar mijn mening is indirect bestuurder Y pas gebonden aan die 'onherroepelijk vastgestelde aansprakelijkheid' van de rechtspersoon-bestuurder (Holding) als dat oordeel is geveld in een procedure waarin hij als partij is betrokken. Pas dan zal dat oordeel - ook tegenover Y - gezag van gewijsde hebben. Maar wat is dan de zin van het arrest van de Hoge Raad? Dat is, in mijn visie, dat onrechtmatig handelen dat feitelijk ligt besloten in gedragingen van indirect bestuurder $\mathrm{X}$, in beginsel ook geldt als onrechtmatig handelen van indirect bestuurder Y, behoudens disculpatie door Y. De Hoge Raad zal niet hebben bedoeld dat $Y$ het gezag van gewijsde dat er is tussen enerzijds de crediteur van de bestuurde vennootschap en anderzijds de rechtspersoon-bestuurder en de (mede) indirect bestuurder X tegen zich zal moeten laten gelden. Dat lijkt mij althans echt een brug te ver.

Laten we dit alles meenemen naar de analyse van de uitspraak van de Rechtbank Midden-Nederland. De rechtspersoon-bestuurder, BV B, zit vast aan het oordeel dat de Beklamel-norm door haar is geschonden, omdat ze niet in verzet is gekomen. Maar haar bestuurder, indirect bestuurder $C$, die wel in verzet is gekomen, kan als opposant niet het recht worden ontzegd alsnog te weerspreken dat er sprake is van handelen in strijd met de Beklamel-norm door BV B. C staat buiten 
het gezag van gewijsde dat er is in de relatie tussen de crediteur van de bestuurde bv, BV A, en haar rechtspersoon-bestuurder. Is de consequentie van deze redenering dan dat zich de vreemde situatie kan voordoen dat de rechtspersoonbestuurder geacht wordt onrechtmatig te hebben gehandeld, terwijl dat ten aanzien van zijn enig bestuurder $C$ (in verzet) niet het geval blijkt te zijn? Inderdaad, dat is de consequentie, in mijn visie. Maar zo vreemd is dat niet, dat is nu eenmaal de consequentie van het leerstuk van het gezag van gewijsde.

Sommigen reageren op een casus als deze: als $C$ nou maar ook BV B verzet had laten aantekenen, dan zou deze hele discussie niet zijn ontstaan. Een goed punt, maar ik wijs er toch nog maar eens op dat er goede redenen kunnen zijn waarom dat niet is gebeurd: $C$ is inmiddels afgetreden of ontslagen, of BV B beschikt niet over middelen om zich van rechtsbijstand te voorzien, en inschakeling van een advocaat door BV B zou wellicht tot een Beklamel-schuld ten laste van C kunnen leiden. Maar zelfs als $C$ het wel in zijn macht zou hebben BV B verzet te laten aantekenen, dan zou het enig juiste antwoord op de gestelde vraag mijns inziens luiden: $C$ moet in verzet de gelegenheid hebben zijn eigen verweer tegen de gestelde (maar jegens de bestuurder-rechtspersoon inmiddels vaststaande) schending van de Beklamel-norm te laten beoordelen.

\section{De bestuurdersaansprakelijkheid ex art. 6:162 BW en schade}

Ik stap over op een ander aspect van bestuurdersaansprakelijkheid en processuele verweermogelijkheden. In het kort de casus die mij voor ogen staat en die ik ontleen aan het vonnis van de Rechtbank Limburg van 28 november 2018. ${ }^{14}$ Een bv wordt op vordering van een crediteur door de rechter veroordeeld tot betaling van onbetaald gebleven facturen, buitengerechtelijke incassokosten en de proceskosten. Kort voordat deze veroordeling is uitgesproken, blijkt de bv te zijn 'geturboliquideerd'. ${ }^{15}$ Het vonnis tegen de bv gaat in kracht van gewijsde. De stelling van de crediteur is nu dat de enig bestuurder, B, de bv heeft leeggehaald en dat hij daardoor het verhaal op het vermogen van de bv doelbewust heeft gefrustreerd. Hij betrekt B in rechte. De rechtbank oordeelt dat B inderdaad onrechtmatig heeft gehandeld en komt dan toe aan de beoordeling van het verweer van bestuurder $B$ over de omvang van de schade, bestaande uit de zojuist genoemde optelsom van onbetaald gebleven facturen, de incasso- en proceskosten. De rechtbank overweegt dan:

'De stellingen van [bestuurder B] gaan eraan voorbij dat het vonnis van 24 mei 2017 tussen [de crediteur] en de BV inmiddels kracht van gewijsde heeft gekregen. Daarmee staat vast dat de BV de in het dictum van het vonnis genoemde bedragen aan [de crediteur] moet voldoen. Het is dit vonnis (...) waarop [de crediteur] nu zijn vordering tot schadevergoeding heeft geba-

14 Rb. Limburg 28 november 2018, ECLI:NL:RBLIM:2018:11169.

15 Ontbonden en dadelijk opgehouden te bestaan wegens het volledig ontbreken van baten, art. 2:19 lid 4 BW. 
seerd. Dit betekent dat de stellingen van [bestuurder B] die zijn gericht tegen de facturen en de overige oorspronkelijke vorderingen van [de crediteur] jegens de Handelsonderneming geen doel treffen.'

Bestuurder B heeft de verschuldigdheid van de facturen door de bv dus betwist, maar de rechtbank vindt dat die discussie gesloten is: het oordeel over de relatie tussen de crediteur en de bv, dat wil zeggen het oordeel over de omvang van de schuld van de bv aan de crediteur, is in kracht van gewijsde gegaan, en dus staat de schade van de crediteur ook tegenover bestuurder B vast, zo begrijp ik het oordeel van de rechtbank. Deze visie van de rechtbank heeft de charme van efficiency: de rechtbank hoeft toch zeker niet tweemaal te oordelen over diezelfde facturen? Maar we zagen eerder dat het gezag van gewijsde in de relatie tussen de crediteur en de bv de aansprakelijk gestelde bestuurder B niet deert. Weliswaar staat definitief vast dat de bv een aanzienlijk bedrag schuldig is aan de crediteur, maar daarmee is nog niet gezegd dat bestuurder B, mocht de rechtbank in zijn aansprakelijkheidsprocedure oordelen dat hij zich schuldig heeft gemaakt aan verhaalsfrustratie, dan ook direct dit bedrag als schadevergoeding verschuldigd is. Het is de crediteur die zal moeten stellen en, zo nodig, bewijzen welke schade bestuurder B door diens onrechtmatige gedraging heeft veroorzaakt. De bestuurder, op zijn beurt, kan zich verweren tegen de omvang van de schade en de toerekening van gestelde schade aan zijn gedrag. En die omvang betreft dus ook de vraag: is er nou werkelijk een schuld ontstaan ten laste van de bv ter hoogte van het bedrag tot betaling waarvan de bv is veroordeeld? Inderdaad is het dus mogelijk dat de rechter zich andermaal moet buigen over de facturen, in de context van de vraag of het totaal van onbetaald gebleven facturen als schade aan het onrechtmatige gedrag van de bestuurder kan worden toegerekend. Dat lijkt mij ook echt de juiste weg, want anders zou de bestuurder B in wezen geheel worden buitengesloten als het gaat om de vraag welke schade aan diens gedrag kan worden toegerekend.

Een iets andere casus werd recent beoordeeld door het Gerechtshof Amsterdam. ${ }^{16}$ Het ging om de vraag of een aansprakelijk gestelde bestuurder van een rechtspersoon nog wel verweren kon aanvoeren die primair de positie van de rechtspersoon betroffen, maar die de tot hem gerichte, op ongerechtvaardigde verrijking gebaseerde, vordering ook konden beïnvloeden. Het hof overwoog:

'ING heeft betoogd dat de grieven van [appellant] tegen overwegingen van de rechtbank die de vordering tegen Adventure Gift [de door appellant bestuurde rechtspersoon die inmiddels had opgehouden te bestaan; HV] betreffen, niet kunnen slagen, omdat Adventure Gift niet in hoger beroep is gekomen.

Dit betoog wordt verworpen. Indien de eerste rechter een vordering tegen twee gedaagden heeft toegewezen, kan elk van beide gedaagden daartegen hoger beroep instellen, ook in het geval dat de medegedaagde dat niet doet. 
De appellant kan dan grieven aanvoeren tegen alle beslissingen van de eerste rechter die hem in zijn belangen raken. Zo is het mogelijk dat ten opzichte van de appellant een uitspraak van de eerste rechter wordt vernietigd en beslissingen in die uitspraak dus geen gezag van gewijsde jegens de appellant krijgen, terwijl de uitspraak ten opzichte van de medegedaagde in kracht van gewijsde gaat en de beslissingen daarin jegens de medegedaagde gezag van gewijsde krijgen. Het voorgaande is anders, indien sprake is van een processueel ondeelbare rechtsverhouding, maar terecht is niet aangevoerd dat daarvan sprake is in dit geval. Alle grieven van [appellant] dienen dan ook beoordeeld te worden.'

Op dat oordeel is niets af te dingen, dunkt me, en het past goed in het betoog over de beperkingen van het gezag van gewijsde. In dezelfde lijn oordeelde enige tijd geleden het Gerechtshof Den Haag, toen het zich over een op onrechtmatige daad gebaseerde bestuurdersaansprakelijkheid moest buigen. De crediteur had inmiddels een vonnis op de bv, en dat vonnis was in kracht van gewijsde gegaan. Kort en goed was daarin geoordeeld dat de bv wanprestatie had gepleegd. Toen vervolgens de bestuurders op grond van onrechtmatige daad in rechte werden betrokken - de bv kwam haar verplichtingen niet na omdat zij niet over middelen beschikte -, wilden zij het verweer voeren dat er geen sprake was van wanprestatie van de bv. Maar kon dat nog wel? Nee, aldus de crediteur, de wanprestatie stond vast. Het hof oordeelde anders:

'Het vonnis dat is gewezen tegen [de bv] heeft geen gezag van gewijsde ten opzichte van de (oud-)bestuurders van die vennootschap. Het staat de aangesproken bestuurders reeds daarom vrij om in het kader van de onderhavige procedure verweer te voeren tegen de stellingen van [de crediteur] over de inhoud en de omvang van de verplichtingen van [de bv]. Het bestaan en de omvang van die verplichtingen is immers bepalend voor de grootte van de schade waarvan in dit geding van de (oud-)bestuurders vergoeding wordt gevorderd. $^{17}$

\section{Afronding}

Ik hoop duidelijk te hebben gemaakt dat het leerstuk van het gezag van gewijsde wat (meer) aandacht vraagt in zaken van bestuurdersaansprakelijkheid. Het is goed stil te staan bij de positie van de hoofdelijk verbonden debiteur in het algemeen en te beseffen dat schuldenaren van een hoofdelijke verbintenis zelfstandig verbonden zijn tegenover de schuldeiser. We zagen dat de bewijslastregel die de Hoge Raad in zijn arrest Le Roux uit 2017 introduceerde de leer van het gezag van gewijsde onverlet laat. En de bestuurder die wegens onrechtmatig handelen tot schadevergoeding wordt aangesproken, zit niet zonder meer vast - waar het de

17 Hof Den Haag 2 februari 2016, ECLI:NL:GHDHA:2016:86, r.o. 4.2 en 4.3. Ik maakte deel uit van de combinatie die dit arrest wees. Zie het (art. 81 Wet RO-)oordeel in cassatie: HR 19 mei 2017, ECLI:NL:HR:2017:941. 
omvang van de schade betreft - aan de veroordeling van de bv zelf bij een in kracht van gewijsde gegaan vonnis.

Ik heb me hierboven beperkt tot de positie van de aansprakelijk gestelde (indirect) bestuurder. Het moge duidelijk zijn dat er ook in andere aansprakelijkheidsverhoudingen op het ondernemingsrechtelijk speelveld oplettendheid in het licht van het besproken procesrechtelijk leerstuk geboden is. Ik denk aan art. 2:403-aansprakelijkheden (is de ex art. 2:403 BW aansprakelijke moedervennootschap gebonden aan een in kracht van gewijsde gegane veroordeling van de dochtermaatschappij?) en aansprakelijkheden op het terrein van het personenvennootschapsrecht (kan een hoofdelijk aansprakelijke vennoot van de vof nog enig verweer voeren tegen diens aansprakelijkheid als de veroordeling van de vof op vordering van de crediteur onherroepelijk is geworden? ${ }^{18}$ ). Er valt dus nog wel wat meer over dit onderwerp over te zeggen.

18 Een vraag waarover de Hoge Raad zich boog en deze van een duidelijk antwoord voorzag, in HR 13 december 2002, ECLI:NL:HR:2002:AE9261, NJ 2004/212 (Bon Appetit). 